\title{
Expression of Fos-related Antigens in the Nucleus Accumbens during Opiate Withdrawal and Their Attenuation by a D2 Dopamine Receptor Agonist
}

\author{
Carrie L. Walters, M.S., Gary Aston-Jones, Ph.D., and Jonathan P. Druhan, Ph.D.
}

Previous studies from this laboratory indicated that D2 dopamine (DA) receptors within the nucleus accumbens (NAc) are important for regulating somatic signs of opiate withdrawal. The present study measured the expression of Fos-related antigens (FRAs) within the NAc during opiate withdrawal to determine whether decreases in somatic withdrawal signs produced by a D2 receptor agonist are accompanied by related changes in accumbens neuronal activity. In an initial experiment, quantitative analyses of FRA immunoreactivity revealed increases in the number of FRA-positive cells throughout the NAc of opiate dependent animals undergoing naltrexone-precipitated withdrawal relative to dependent or non-dependent animals that did not experience withdrawal. A second experiment showed that somatic signs and FRA expression within the NAc could each be attenuated when the $D 2$ agonist propylnorapomorphine (NPA; 0.1 or $0.3 \mathrm{mg} / \mathrm{kg}$, i.p.) was administered prior to naltrexone-precipitated withdrawal. These findings suggest that D2 regulation of neuronal activity within the NAc may be important for the expression of opiate withdrawal symptoms.

[Neuropsychopharmacology 23:307-315, 2000] (C) 2000 American College of Neuropsychopharmacology. Published by Elsevier Science Inc. All rights reserved
KEY WORDS: Nucleus accumbens; Fos-related antigens; Dopamine receptors; Opiate withdrawal; Morphine; Drug abuse

The abrupt cessation of chronic opiate use results in a well-characterized withdrawal syndrome that includes symptoms of nausea, dysphoria, and anxiety. This syndrome is sufficiently adverse that opiate abusers will continue to use drugs to relieve the symptoms of withdrawal. In fact, the need to self-medicate has been identified as an important factor contributing to the mainte-

From the Center for Neurobiology and Behavior, Department of Psychiatry, University of Pennsylvania Medical Center, Philadelphia, PA.

Address correspondence to: Dr. J.P. Druhan, VA Medical Center, Mail Code 151, University and Woodland Aves, Philadelphia, PA 19104.

Received November 1, 1999; revised March 7, 2000; accepted March 10, 2000 nance of opiate use, and a major impediment to successful drug detoxification and rehabilitation (Schulteis and Koob 1996).

Studies of the neurobiological basis for opiate withdrawal have identified a potential role for dopaminergic processes within the nucleus accumbens (NAc) in the expression of opiate withdrawal symptoms. This involvement of the NAc in opiate withdrawal was first suggested by findings that intra-NAc infusions of the quaternary opiate antagonist methylnaloxinium could disrupt operant responding for food and induce conditioned aversions for environments associated with the central infusion (Koob et al. 1989; Stinus et al. 1990). Subsequent in vivo microdialysis studies revealed that extracellular dopamine (DA) levels within the NAc were reduced during both naloxone-precipitated and abstinence-induced opiate withdrawal, thus implicating DA processes within the NAc in the expression of 
withdrawal symptoms (Acquas et al. 1991; Crippens and Robinson 1994; Rossetti et al. 1992; Shaham et al. 1996). Studies in our laboratory have shown that somatic signs of opiate withdrawal can be elicited by infusions of a D2 DA antagonist, whereas somatic signs precipitated by systemic naloxone injections can be abolished by intra-NAc infusions of a D2 receptor agonist (Harris and Aston-Jones 1994).

The present study further examined the role of NAc processes in opiate withdrawal by assessing whether opiate withdrawal states were associated with changes in neuronal activity within the NAc, and whether any measured changes could be reversed when somatic signs of opiate withdrawal were alleviated by systemic injections of the D2 agonist propylnorapomorphine (NPA). To accomplish this, we measured withdrawalinduced changes in the expression of immediate early gene (IEG) products within NAc cells. Changes in neuronal activity often result in the induction of IEGs that, in turn, promote the synthesis of various intracellular constituents including Fos or Fos-related proteins. The presence of Fos-related antigen (FRA) in cell nuclei can be detected immunohistochemically to identify cells that have been influenced by specific experimental treatments (Dragunow and Faull 1989; Morgan and Curran 1991; Sagar et al. 1988). Several studies have used this technique successfully to identify CNS regions influenced by specific pharmacological or behavioral manipulations (Brown et al. 1992; DiNardo and Travers 1997; Pfaus et al. 1996), including opiate withdrawal (Stornetta et al. 1993). Our studies employed FRA immunohistochemistry to examine withdrawal-related neuronal activity within specific subregions of the NAc, and to determine whether stimulation of D2 receptors could interfere with this activity.

\section{MATERIALS AND METHODS}

\section{Subjects}

Male Sprague Dawley rats (Taconic Farms Inc., Germantown, NY) weighing 230-270 g were housed two per cage in a $21^{\circ} \mathrm{C}$ humidity-controlled AAALAC-approved animal-care facility with food and water available ad libitum. The rooms were on a 12-hour light/dark cycle (lights on at 7 A.M.). All experiments were performed during the light cycle from 9 A.M. to 2 P.M.

\section{Behavioral Testing Procedures}

Each experiment consisted of a four-day drug treatment/behavioral testing phase, followed by immunohistochemistry and quantification of FRAs. On Day 1 of the experiment, all rats were briefly anesthetized with Halothane (Halocarbon Laboratories, North Augusta, SC), and a small intrascapular incision was made. Rats designated to become dependent had one $75 \mathrm{mg}$ morphine pellet (National Institute on Drug Abuse supply) implanted subcutaneously, whereas the remaining animals had the incision closed immediately with a wound clip. On Day 2, the animals were again anesthetized and the incision was reopened. The morphine-dependent group received two additional $75 \mathrm{mg}$ pellets, whereas sham-operated animals again had the wound immediately closed. On Day 3, the rats were brought to the test room, given an i.p. injection of vehicle solution, and placed in the test cages individually for $30 \mathrm{~min}$ to acclimate to the surroundings. This session was given to minimize FRA expression that might occur as a result of exposure to a novel testing procedure. On Day 4, the rats were observed for somatic signs of withdrawal after specific pharmacological treatments (described below). For these observations, the rats were placed individually into plastic test cages $(45 \times 24 \times 20 \mathrm{~cm})$ and the frequencies of wet dog shakes, teeth chatter, writhing, diarrhea, and jumping were measured continuously for $30 \mathrm{~min}$ by an observer who was blind to the treatment conditions. These somatic signs have been used frequently by our laboratory to measure physical withdrawal responses (see Delfs et al. 2000; Harris and Aston-Jones 1993, 1994), and observer reliability in scoring these measures was established prior to the start of experimentation.

\section{Drugs}

Morphine pellets were obtained from the NIDA Drug Supply (Research Triangle Park, NC), with each pellet formulated to contain $75 \mathrm{mg}$ of morphine alkaloid base, $68.5 \mathrm{mg}$ microcrystalline cellulose, $1.5 \mathrm{mg}$ magnesium stearate, and $2.5 \mathrm{mg}$ colloidal silicon dioxide. Naltrexone HCL (Research Biochemicals International, Natick, MA) was dissolved in $0.9 \%$ sodium chloride solution and injected i.p. in a volume of $1 \mathrm{ml} / \mathrm{kg}$. Propylnorapomorphine (NPA; Research Biochemicals International, Natick, MA) was dissolved in $0.001 \mathrm{~N} \mathrm{HCl}$ and injected i.p. in a volume of $1 \mathrm{ml} / \mathrm{kg}$. Lithium chloride (Fisher Scientific Company, Fair Lawn, NJ) was dissolved in sterile water and injected i.p. in a volume of $10 \mathrm{ml} / \mathrm{kg}$.

\section{Experiment 1: Measurement of Withdrawal-Induced FRA Expression in the NAc}

Sixteen rats were given morphine pellets or sham surgeries (as described above) and then randomly assigned to one of four groups ( $N=4$ rats/grp): a morphinedependent group injected with naltrexone, a morphinedependent group injected with saline, a sham-operated group injected with naltrexone, and a sham-operated group injected with saline. On day four, the rats were injected with either saline or naltrexone $(1.0 \mathrm{mg} / \mathrm{kg}$, i.p.), and then observed in the test cages for $30 \mathrm{~min}$ as 
described above. All rats were euthanized and perfused $90 \mathrm{~min}$ after the end of this observation period, and their brains were extracted for later immunohistochemical analyses (see below).

A control experiment was performed to assess whether changes in NAc FRAs could be related to general distress. Two groups of rats were given sham surgeries on Days 1 and 2 and then acclimatized to the testing environment on Day 3. On Day 4, the animals were injected with either lithium chloride ( $\mathrm{LiCl} ; 120 \mathrm{mg} / \mathrm{kg}$, ip) or sterile water, and then placed in the test cages for $30 \mathrm{~min}$. The rats were observed for withdrawal-like symptoms during this period and then perfused $90 \mathrm{~min}$ later.

\section{Experiment 2: Effects of NPA on Withdrawal-Induced FRA Expression in the NAc}

Twenty-three rats were made dependent using the protocol described above, and then randomly assigned to one of six groups ( $N=3$ or $4 /$ grp). On Day 4 of the experiment, three of these groups were first given an i.p. injection of one of two doses of NPA $(0.1$ or $0.3 \mathrm{mg} / \mathrm{kg}$ ) or its vehicle $(0.001 \mathrm{~N} \mathrm{HCl})$, and they were then given naltrexone $(1.0 \mathrm{mg} / \mathrm{kg}$, i.p.) $10 \mathrm{~min}$ later. The remaining three groups received the same initial treatments (i.e., NPA or its vehicle) followed 10 min later by a saline injection. All rats were then observed for signs of withdrawal over a $30 \mathrm{~min}$ period, and then perfused $90 \mathrm{~min}$ later.

\section{FRA Immunohistochemistry}

All rats were anesthetized with Nembutal $(50 \mathrm{mg} / \mathrm{kg}$, i.p.) $90 \mathrm{~min}$ after the end of the behavioral observation period, and then perfused transcardially with lactated ringers solution $(30 \mathrm{sec})$ followed by $4 \%$ paraformaldehyde ( $25 \mathrm{~min})$. The brains were removed and post-fixed in $4 \%$ paraformaldehyde for $11 / 2$ hours and cryoprotected in $20 \%$ sucrose at $4^{\circ} \mathrm{C}$ until they were sliced.

The brains were subsequently frozen and sectioned coronally into $40 \mu \mathrm{m}$ slices that were placed immediately into 0.1M phosphate buffered saline (PBS; $\mathrm{pH} 7.4$ ). The slices were later incubated with $2 \%$ hydrogen peroxide in PBS, rinsed twice in PBS and stored overnight (at $4^{\circ} \mathrm{C}$ ) in PBS with $0.1 \%$ sodium azide (PBS-Az). They were then incubated overnight $\left(\right.$ at $\left.4^{\circ} \mathrm{C}\right)$ with $2 \%$ normal donkey serum (NDS; Jackson Immunoresearch Laboratories, West Grove, PA, USA) in PBS-Az with $0.3 \%$ Triton-X (PBS-Az-Tx) to block non-specific antibody binding. The slices were subsequently incubated for 48 hours with a 1:50,000 dilution of primary antibody (rabbit anti-Fos, Oncogene Sciences) in $2 \%$ NDS (at $4^{\circ} \mathrm{C}$ ).

The tissue was then rinsed in PBS-Tx and transferred to the secondary antibody (biotinylated donkey antirabbit, 1:500 in PBS-Tx; Jackson) for $90 \mathrm{~min}$ at $22^{\circ} \mathrm{C}$ and thereafter transferred to Avidin-Biotin Complex (ABC, 1:500 in PBS-Tx; Jackson) for another $90 \mathrm{~min}$ at room temperature. The tissue was reacted in $0.02 \% 3,3^{\prime}$-diaminobenzidine (DAB; Sigma, St. Louis, MO, USA) with $0.0002 \%$ hydrogen peroxide and $0.6 \%$ nickel ammonium sulfate in $0.05 \mathrm{M}$ Tris buffer ( $\mathrm{pH} 7.6$ ) for $90 \mathrm{sec}-$ onds. The reaction was terminated by transferring slices to Tris buffer and then rinsed before storing in PBS-Az at $4^{\circ} \mathrm{C}$. The slices were mounted onto gelatin-coated slides, dehydrated through a graded alcohol series and finally cover slipped with Permount mounting medium.

\section{Quantification and Analyses}

Somatic signs were quantified by counting the number of occurrences of each behavioral response emitted during the 30-min observation period. The values for each behavioral response were then analyzed using planned orthogonal comparison procedures with independent F-tests conducted on specific pairs of means. The performance of these a priori comparisons instead of full analyses of variance is appropriate in circumstances where enhanced statistical power is desired to evaluate a limited number of specific hypotheses within a data set (see Hays 1981). Experiment-wide variance estimates were used for each comparison, and changes in any particular withdrawal response were considered significant at $p<.05$.

FRA expression in the NAc was quantified from camera lucida drawings of FRA-positive cells in coronal sections corresponding to the $+0.7,+1.6$, and $+2.2 \mathrm{~mm}$ coordinates anterior to bregma in the Paxinos and Watson atlas (1998) (see Figure 1). The most anterior section $(+2.2)$ represents a level which includes the rostral pole of the NAc. The two posterior sections represent midlevel and extreme caudal levels of the NAc in which distinct core and shell regions can be anatomically differentiated (Alheid and Heimer 1996; Zahm and Brog 1992).

The core and shell subregions were distinguished by their easily observable boundaries under light microscopy with a 10X objective. One representative section from each level was quantified and the section chosen was similar across experimental groups. FRA-positive cells were identified by the presence of dense immunohistochemical staining within the nuclei (Figure 2). These cells were quantified by constructing cameralucida drawings of the FRA-positive nuclei within the NAc of each hemisphere. The number of labeled nuclei within the rostral pole of the NAc, and within the shell and core subregions of the two more caudal sections were then counted from the camera-lucida drawings and the mean number of cells per subregion (averaged across both hemispheres) were calculated. The construction of the camera-lucida drawings and quantifica- 

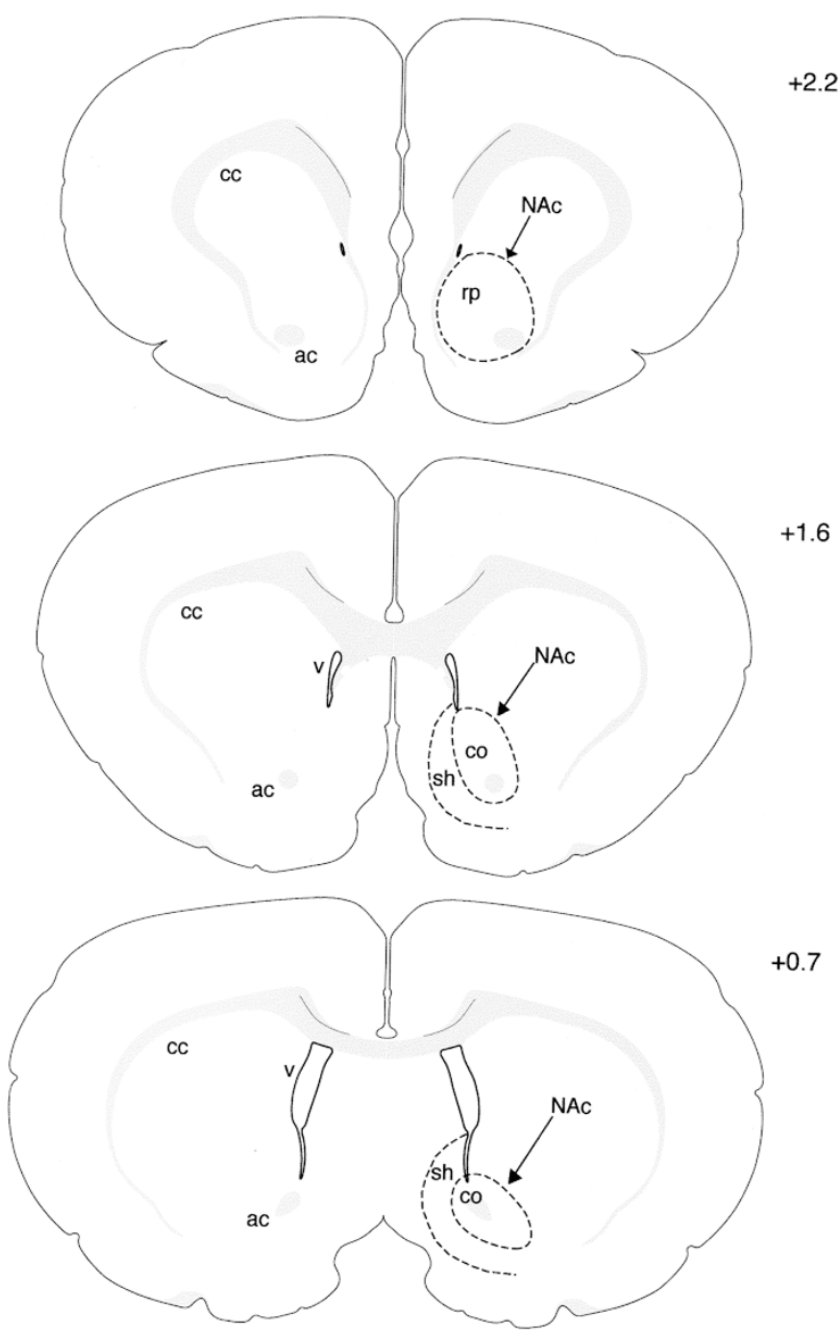

Figure 1. Schematic representations of sections used for quantification of FRA-positive nuclei. The boundaries of each area quantified are indicated by dashed lines within the sections. The number to the right of each section corresponds to the longitudinal coordinate in the atlas of Paxinos and Watson (1998). Abbreviations: ac, anterior commissure; cc, corpus callosum; co, core of the accumbens; v, lateral ventricle; NAc, nucleus accumbens; rp, rostral pole of the accumbens; sh, shell of the accumbens.

tion of FRA-positive nuclei were performed without knowledge of the experimental treatments to eliminate experimenter bias. The numbers of FRA-positive nuclei were analyzed using planned orthogonal contrast procedures, with effects considered significant at $p<.05$.

\section{RESULTS}

\section{Experiment 1: Measurement of Withdrawal-Induced FRA Expression in the NAc}

Analyses of the behavioral data from Experiment 1 revealed significant increases in the number of wet dog shakes, teeth chatters, diarrhea, and jumping responses emitted by morphine-withdrawn rats after naltrexone relative to the morphine-implanted or sham-operated control groups (see Figure 3a) (ranges of $F$ values: $\mathrm{F}(1,11)=14.98$ to 20.39 for wet dog shakes, $\mathrm{F}(1,11)=$ 82.42 to 96.15 for teeth chatter, $\mathrm{F}(1,11)=101.31$ to 123.04 for diarrhea, $\mathrm{F}(1,11)=4.45$ to 5.19 for jumping; $p<.05$ for all comparisons).

Subsequent examination of immunohistochemically labeled sections taken from these animals indicated that the behavioral withdrawal responses were associated with strong increases in FRA expression throughout the NAc (e.g., see Figure 2). Statistical analyses confirmed that opiate withdrawn rats had significantly higher numbers of FRA-positive nuclei in each subregion of the NAc examined (the rostral pole, and the core and shell subregions of each caudal section) relative to the numbers found in sections taken from control groups (Figure $3 b$ ) (ranges of $F$ values: $F(1,11)=29.93$ to 43.17 for rostral pole, $\mathrm{F}(1,11)=87.35$ to 101.27 for mid-level core, $\mathrm{F}(1,11)=18.23$ to 21.01 for mid-level shell, $\mathrm{F}(1,11)=$ 94.58 to 121.16 for caudal core, $\mathrm{F}(1,11)=43.14$ to 53.49 for caudal shell; $p<.05$ for all comparisons).

The animals that received $\mathrm{LiCl}$ looked lethargic and sick, but they did not show any withdrawal-like behavioral responses. These rats also did not have significantly greater numbers of FRA-positive nuclei within various subregions of the NAc than vehicle-injected control rats (Table 1), indicating that general malaise was not a sufficient condition for inducing FRA expression in the NAc.

\section{Experiment 2: Effects of NPA on Withdrawal- Induced FRA Expression in the NAc}

Rats subjected to naltrexone-precipitated withdrawal after receiving only vehicle pretreatments showed strong somatic withdrawal responses that were similar to those shown by opiate withdrawn rats in Experiment 1 (Figure 4a). In contrast, rats pretreated with 0.1 or 0.3 $\mathrm{mg} / \mathrm{kg}$ NPA showed significant reductions in the numbers of wet dog shakes $(F(1,18)=20.17$ and $F(1,18)=$ 27.46; $p<.0005$ for each comparison), teeth chatter $(\mathrm{F}(1,18)=25.44$ and $\mathrm{F}(1,18)=34.75 ; p<.0001$ for each comparison), and diarrhea responses $(\mathrm{F}(1,18)=7.54$ and $\mathrm{F}(1,18)=7.54 ; p<.025$ for each comparison). These doses of NPA also produced slight increases in jumping behavior, but these trends did not reach statistical significance ( $p=0.14$ for vehicle vs. $0.3 \mathrm{mg} / \mathrm{kg}$ ).

As in Experiment 1, the behavioral responses to opiate withdrawal were associated with high levels of FRA expression throughout the NAc of vehicle-pretreated rats (Figure $4 \mathrm{~b}$ ). The overall pattern and magnitude of this FRA expression was similar to that observed in Experiment 1, except that more FRA-positive cells were observed within the rostral pole in the second experi- 

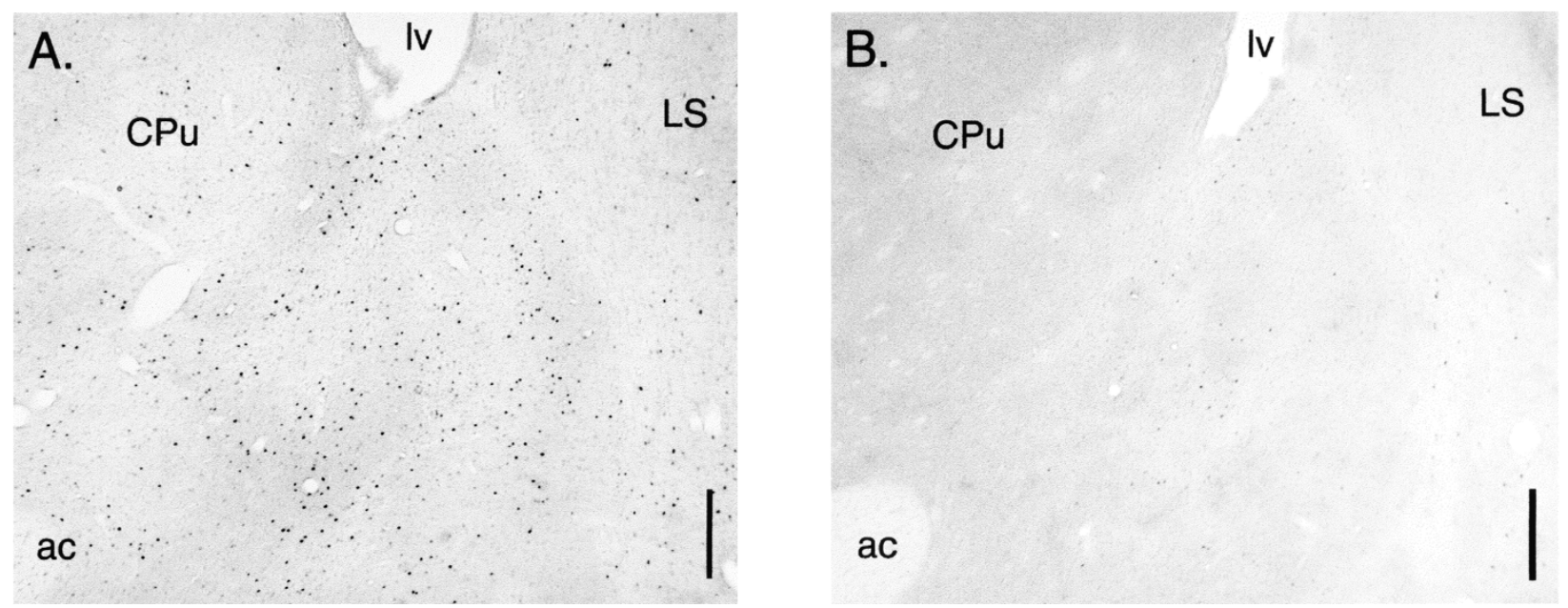

Figure 2. Photomicrographs showing increased FRA expression within the NAc of a morphine-dependent rat subjected to naltrexone-precipitated withdrawal (A), relative to a non-dependent rat given naltrexone (B). Each photomicrograph displays a coronal section of the dorsomedial NAc from one hemisphere, at a level corresponding to the $+1.6 \mathrm{~mm}$ longitudinal coordinate in the atlas of Paxinos and Watson (1998). Similar differences were observed in NAc sections corresponding to the +2.2 and +0.7 longitudinal coordinates, and when sections from opiate-withdrawn rats were compared to sections from dependent or non-dependent control rats given only saline injections. The photomicrographs were taken with a 5X objective, and each scale bar equals $200 \mu \mathrm{m}$. Abbreviations: $\mathrm{CPu}$, caudate-putamen; LS, lateral septum; lv, lateral ventricle; ac, anterior commissure.

ment. Statistical analyses indicated that this FRA expression was significantly reduced within the rostral pole $(\mathrm{F}(1,17)=7.32, p<.025)$ and within the core of the mid-level and caudal sections $(\mathrm{F}(1,18)=6.19, p<.025$ and $\mathrm{F}(1,18)=4.72, p<.05$, respectively) of rats pretreated with the higher dose of NPA $(0.3 \mathrm{mg} / \mathrm{kg})$. The lower dose of NPA $(0.1 \mathrm{mg} / \mathrm{kg})$ reduced FRA expression within the core and shell of mid-level sections $(\mathrm{F}(1,18)=6.04, p<.025$ and $\mathrm{F}(1,18)=5.06, p<.05$, respectively), although the latter effects within the midlevel shell were not reliable as they failed to reach significance at the higher dose of NPA $(p=.24)$.

Withdrawal-induced FRA expression in the shell portion of the most caudal section examined $(0.7 \mathrm{~mm}$ rostral to bregma) was not affected by either dose of NPA. Importantly, NPA did not affect constitutive levels of FRA expression within NAc subregions of rats that were not subjected to naltrexone-precipitated opiate withdrawal (Figure 4c). Rather, NPA appeared to specifically reduce FRA expression that was induced by opiate withdrawal.

Analyses of the lateral septum, a structure immediately dorsal to the Nac, revealed evidence of significant withdrawal-induced FRA expression within each of two levels examined $(\mathrm{F}(1,18)=10.70, p<.005$ at 1.6 $\mathrm{mm}$ and $\mathrm{F}(1,18)=8.01, p<.025$ at $0.7 \mathrm{~mm}$ rostral to bregma) (see Table 2). This FRA expression was not affected by pretreatments with NPA, indicating that the effects of the D2 agonist on genomic responses showed regional specificity within the tissue sections examined.

\section{DISCUSSION}

If the NAc is involved in regulating behavioral responses to opiate withdrawal, then changes in neuronal activity should be observed within this structure when rats are subjected to abrupt withdrawal. The present study confirmed this prediction by demonstrating increased FRA expression within the NAc following naltrexone-precipitated withdrawal from prolonged morphine treatment. This increase was observed throughout the rostral-caudal extent of the NAc, and it occurred in both the core and shell subterritories. The increased FRA expression did not appear to be caused by general malaise since the effect did not occur when rats were made ill by administering $\mathrm{LiCl}$. To the extent that FRA expression may be used as a genomic marker of cellular activation (Dragunow and Faull 1989; Morgan and Curran 1991; Sagar et al. 1988), the findings of this study suggest that cells within the NAc are activated during opiate withdrawal. These results concur with those of previous in situ hybridization studies that reported increased c-fos induction within the NAc during withdrawal (Rasmussen et al. 1995; Hayward et al. 1990), and they support hypotheses that suggest a role for the NAc in the regulation of behavioral responses to opiate withdrawal.

The ability of opiate withdrawal to induce FRA expression within the NAc could be related to a variety of functional changes that occur during withdrawal. One such change could involve a decrease in $\mu$ opioid recep- 
tor stimulation within the NAc. Stimulation of these receptors normally results in an inhibition of NAc cellular activity (Hakan and Henriksen 1989; Hakan et al. 1989; Chieng and Williams 1998; Yuan et al. 1992), and an

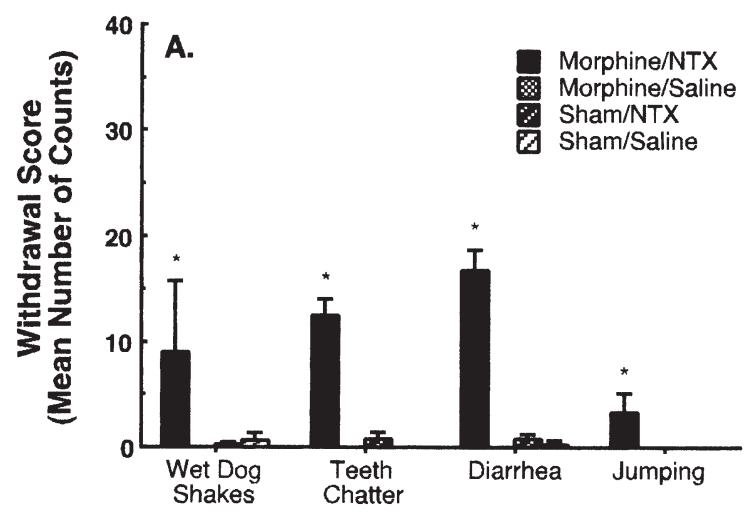

Somatic Withdrawal Sign

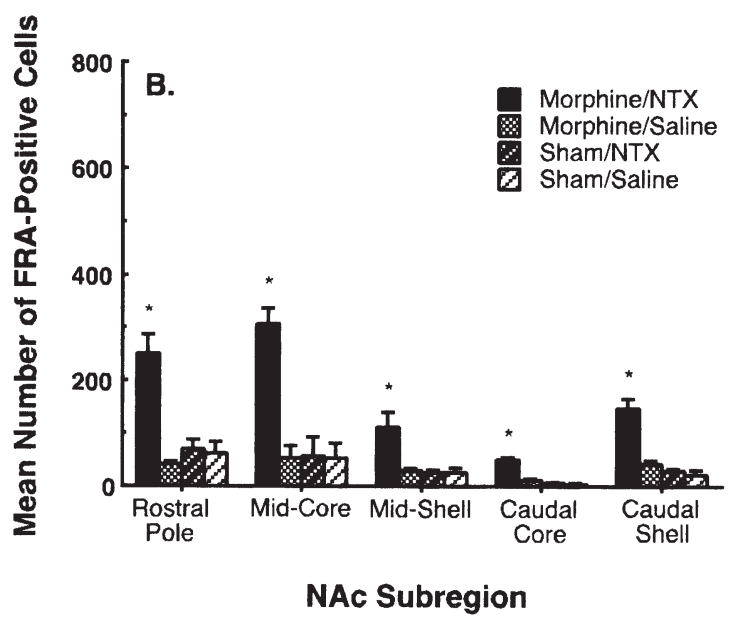

Figure 3. Mean numbers (+ SEMs) of somatic signs (A) and FRA-positive cells (B) within the NAc measured in morphine-dependent rats injected with naltrexone (Morphine/ NTX), morphine-dependent rats injected with saline (Morphine/Saline), sham-operated rats given naltrexone (Sham/ NTX), or sham-operated rats given saline (Sham/Saline). Morphine-dependent rats subjected to naltrexone-precipitated withdrawal showed a significantly higher incidence of wet dog shakes, teeth chattering, diarrhea, and jumping during the 30 min observation period than animals in each of the control groups. Although the rats were observed for writhing, this response rarely occurred (data not shown). Analysis of the numbers of FRA-positive cells within different subregions of the NAc indicated that FRA expression in the Morphine/NTX group was elevated relative to that measured in control groups for each subregion examined. There were no differences observed among the three non-withdrawn control groups in any of the NAc subregions. Asterisks indicate groups that differed significantly from the Sham/Saline group at $p<.05$. abrupt reduction in $\mu$ receptor activation following prolonged stimulation could lead to a rebound activation of NAc cells. This activation could result from the upregulation of adenylyl cyclase activity and increase in cAMP formation that occurs following chronic morphine exposure and subsequent withdrawal (Duman et al. 1988; Terwilliger et al. 1991). Alternatively, the increased FRA expression could result from the sudden decrease in DA receptor stimulation produced when extracellular DA levels decline during opiate withdrawal. DA receptor stimulation normally inhibits cellular activity within the NAc (White and Wang 1986; O'Donnell and Grace 1996), and the decreased stimulation that would occur during opiate withdrawal might result in higher levels of cellular activity within the NAc. A third possible mechanism for the increased FRA expression may be an increase in excitatory amino acid (EAA) transmission within the NAc. Opiate withdrawal stimulates neuronal activation within regions that send EAA projections to the NAc, such as the amygdala, the prefrontal cortex, and the hippocampus (Hayward et al. 1990; Stornetta et al. 1993; Rasmussen et al. 1995). Increased activity within these projections would lead to heightened EAA release within the NAc, and the resulting increase in cellular activation could be responsible for the induction of FRA expression in the NAc during opiate withdrawal.

A second major finding of this study was that withdrawal-induced FRA expression within the NAc could be reduced by NPA, a highly potent and selective D2 agonist that has no affinity for central noradrenergic or serotonergic receptors at the doses administered in this study (Creese et al. 1979; Kohler et al. 1981; Titeler and Seeman 1979). This effect of NPA on FRA expression was evident in the rostral pole and in both the caudal and midlevel sections of the NAc core. Interestingly, NPA failed to reliably affect FRA expression in the NAc shell. These weaker effects of NPA in the shell could be due to a greater sensitivity of this region to activation by opiate withdrawal. In fact, we have noticed that FRA expression is restricted to the dorsomedial region of the caudal shell in rats subjected to mild withdrawal from

Table 1. FRA Expression after LiCl Injections

\begin{tabular}{lcc}
\hline NAc Section & LiCl Injection & Saline Injection \\
\hline Rostral Pole & $57(9)$ & $73(15)$ \\
Mid-Core & $62(18)$ & $71(6)$ \\
Mid-Shell & $37(9)$ & $43(10)$ \\
Caudal Core & $22(7)$ & $19(4)$ \\
Caudal Shell & $72(16)$ & $54(6)$ \\
\hline
\end{tabular}

All results are expressed as the mean $( \pm$ sem) number of FRA-positive nuclei counted at different levels of the NAc in rats after an i.p. injection of either saline or lithium chloride. 


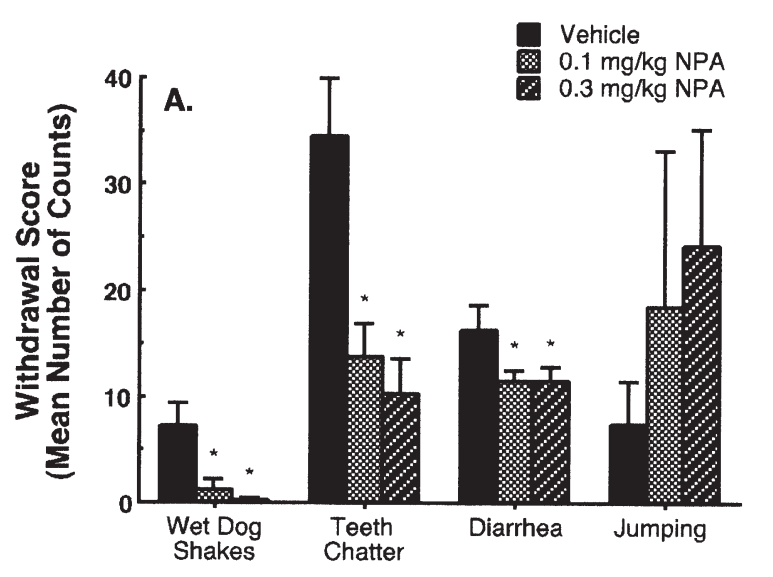

Somatic Withdrawal Sign

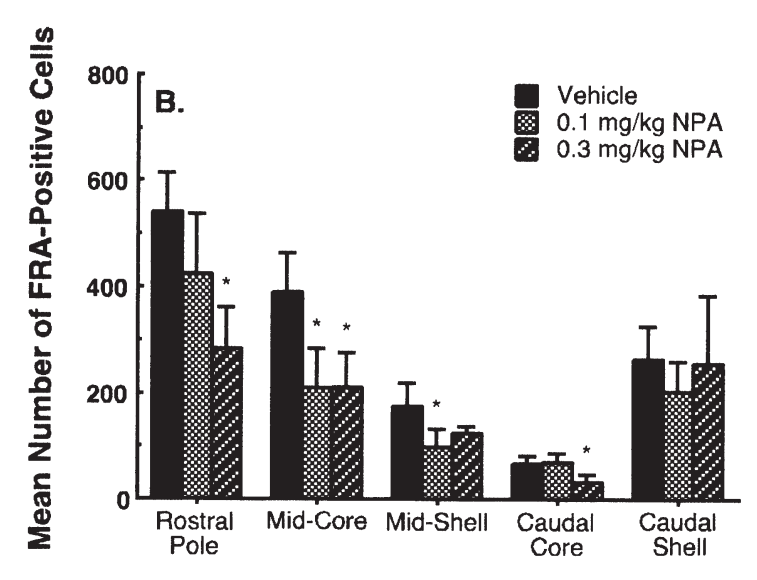

NAc Subregion

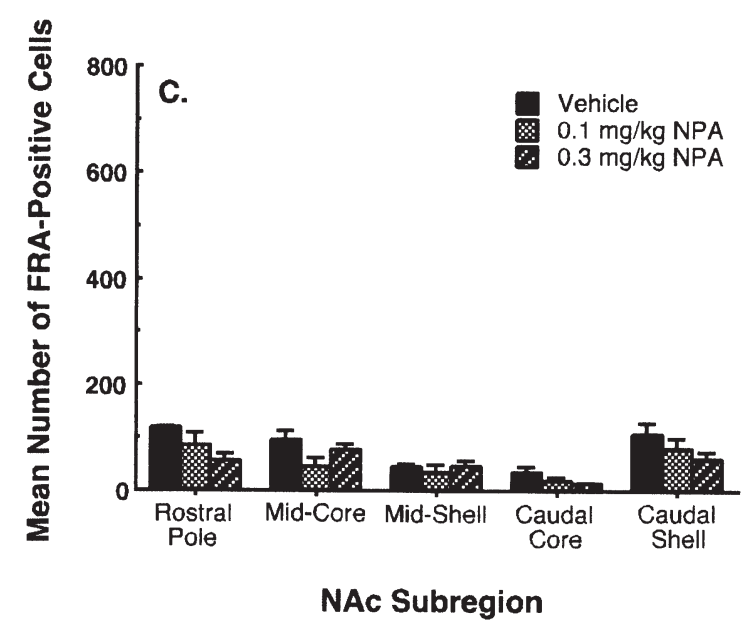

Figure 4. Effects of NPA on somatic signs of withdrawal and on FRA expression within the NAc in morphine-dependent rats. (A) Mean numbers (+ SEMs) of somatic signs measured during a $30 \mathrm{~min}$ observation period in morphinedependent rats subjected to naltrexone-precipitated withdrawal following pretreatments with NPA $(0.1$ or $0.3 \mathrm{mg} /$ $\mathrm{kg}$ ) or vehicle solution. NPA significantly reduced wet dog
Table 2. FRA Expression in Lateral Septum

\begin{tabular}{lccc}
\hline & Vehicle & $\mathbf{0 . 1} \mathbf{~ m g} / \mathbf{k g ~ N P A}$ & $\mathbf{0 . 3} \mathbf{~} \mathbf{~ g} / \mathbf{k g ~ N P A}$ \\
\hline$+1.6 \mathrm{~mm}$ & & & \\
Naltrexone & $77(15)$ & $74(23)$ & $79(6.5)$ \\
Saline & $23(4.3)$ & $25(3.6)$ & $34(2.2)$ \\
$+0.7 \mathrm{~mm}$ & & & \\
Naltrexone & $158(25)$ & $188(20)$ & $183(22)$ \\
Saline & $90(5.9)$ & $75(11)$ & $68(3.2)$ \\
\hline
\end{tabular}

All results are expressed as the mean $( \pm$ sem) number of FRA-positive nuclei counted in the lateral septum of rats within sections corresponding to $1.6 \mathrm{~mm}$ and $0.7 \mathrm{~mm}$ anterior to bregma. All rats were morphinedependent and were given one of three doses of NPA (i.p.) followed by either naltrexone or saline injections (i.p.).

morphine (unpublished observations). This greater sensitivity could be due to the release of noradrenaline (NA) in this region during opiate withdrawal. Recent evidence suggests that the caudal shell of the NAc is substantially innervated by NA fibers from caudal brainstem nuclei (A1 and A2 cell groups), whereas the core and rostral pole subregions are devoid of such inputs (Berridge et al. 1997; Delfs et al. 1998). Opiate withdrawal potently activates NA cells in the caudal medullary cell groups, and increases NA release in the NAc (Stornetta et al. 1993; Baraban et al. 1995; Zhu et al. 1997; McKittrick et al. 1999). Stimulation of NA receptors has been found to increase FRA expression in several brain areas (Stone et al. 1991, 1995; Bing et al. 1992), and a greater activation of NA receptors in the caudal shell may contribute to the neuronal activation in this subregion observed during opiate withdrawal. This heightened activation of NA receptors also may interfere with the ability of D2 receptor stimulation to reduce FRA expression in the NAc shell.

The ability of NPA to concurrently suppress FRA expression within the NAc and somatic signs of with-

shakes, teeth chattering, and diarrhea, and produced nonsignificant increases in jumping. Non-dependent rats given naltrexone in combination with NPA or its vehicle also were observed for somatic signs of withdrawal, but such signs were seldom detected in these treatment groups (data not shown). (B) Mean numbers (+ SEMs) of FRA-positive cells in specific subregions of the NAc for rats pretreated with NPA $(0.1$ or $0.3 \mathrm{mg} / \mathrm{kg}$ ) or vehicle solution prior to naltrexone-precipitated withdrawal. NPA significantly reduced FRA expression in the rostral pole, the mid-level core, and the caudal core subregions. In contrast, this D2 agonist produced inconsistent effects on FRA expression in the midshell subregion, and had no effect on FRA levels within the caudal shell. (C) Mean numbers (+ SEMs) of FRA-positive cells in specific subregions of the NAc for morphine-dependent rats given NPA ( 0.1 or $0.3 \mathrm{mg} / \mathrm{kg}$ ) or vehicle solution in the absence of withdrawal. NPA did not significantly affect baseline levels of FRA expression in these non-withdrawn rats. Asterisks indicate groups that differed significantly from the respective vehicle-treated group at $p<.05$. 
drawal provides correlative evidence that dopaminergic modulation of cellular activity within the NAc may be important for the expression of somatic responses to opiate withdrawal. Indeed, previous studies by Harris and Aston-Jones (1994) have indicated that NAc D2 receptor stimulation can eliminate several somatic responses to opiate withdrawal. However, it is noteworthy that D2 receptor stimulation tended to increase withdrawal-induced jumping responses in the present study (not measured in the Harris and Aston-Jones (1994) study). This trend was consistent with previous reports that DA agonists increase escape-like jumping responses induced by intense withdrawal from chronic opiate exposure (Schulz and Herz 1977; Gomaa et al. 1989; Martin and Takemori 1987). Such findings indicate that D2 receptor stimulation may concurrently decrease some of the behavioral consequences of opiate withdrawal while increasing others. In particular, stimulation of NAc D2 receptors may suppress the somatic malaise and behavioral depression that occurs during opiate withdrawal while exerting a facilitatory effect on overt behavioral responding. This combination of effects could lead to a greater level of behavioral responsiveness whenever NAc D2 receptors are stimulated during opiate withdrawal. Although DA levels in the NAc are generally reduced during withdrawal (Acquas et al. 1991; Crippens and Robinson 1994; Rossetti et al. 1992; Shaham et al. 1996), environmental stimuli that increase DA release may activate D2 receptors and increase an individual's preparedness to engage in drug seeking behaviors. In this manner, D2 processes within the NAc may play a role in regulating the level of behavioral responsiveness to drug related stimuli during periods of abstinence.

\section{ACKNOWLEDGMENTS}

The authors would like to thank Dr. Yan Zhu and Mr. Bryan Wilent for their excellent technical assistance on this project. The work was supported by PHS grants DA10088 to JPD and DA06214 to GAJ.

\section{REFERENCES}

Acquas E, Carboni E, Di Chiara G (1991): Profound depression of mesolimbic dopamine release after morphine withdrawal in dependent rats. Eur J Pharmacol 193: 133-134

Alheid GF, Heimer L (1996): Theories of basal forebrain organization and the "emotional motor system." Prog Brain Res 107:461-484

Baraban SC, Stornetta RL, Guyenet PG (1995): Effects of morphine and morphine withdrawal on adrenergic neurons of the rat rostral ventrolateral medulla. Brain Res 676:245-257
Berridge CW, Stratford TL, Foote SL, Kelley AE (1997): Distribution of dopamine beta-hydroxylase-like immunoreactive fibers within the shell subregion of the nucleus accumbens. Synapse 27:230-241

Bing G, Stone EA, Zhang Y, Filer D (1992): Immunohistochemical studies of noradrenergic-induced expression of c-fos in the rat CNS. Brain Res 592:57-62

Brown EE, Robertson GS, Fibiger HC (1992): Evidence for conditional neuronal activation following exposure to a cocaine-paired environment: Role of forebrain limbic structures. J Neurosci 12:4112-4121

Chieng B, Williams JT (1998): Increased opioid inhibition of GABA release in nucleus accumbens during morphine withdrawal. J Neurosci 18:7033-7039

Creese I, Padgett L, Fazzini E, Lopez F (1979): ${ }^{3} \mathrm{H}-\mathrm{N}-n-p r o-$ pylnorapomorphine: A novel agonist ligand for central dopamine receptors. Eur J Pharmacol 56:411-412

Crippens D, Robinson TE (1994): Withdrawal from morphine or amphetamine: Different effects on dopamine in the ventral-medial striatum studied with microdialysis. Brain Res 650:56-62

Delfs JM, Zhu Y, Druhan JP, Aston-Jones G (1998): Origin of noradrenergic afferents to the shell subregion of the nucleus accumbens: Anterograde and retrograde tracttracing studies in the rat. Brain Res 806:127-140

Delfs JM, Zhu Y, Druhan JP, Aston-Jones G (2000): Noradrenaline in the ventral forebrain is critical for opiate withdrawal-induced aversion. Nature 403:430-434

DiNardo LA, Travers JB (1997): Distribution of fos-like immunoreactivity in the medullary reticular formation of the rat after gustatory elicited ingestion and rejection behaviors. J Neurosci 17:3826-3839

Dragunow M, Faull R (1989): The use of c-fos as a metabolic marker in neuronal pathway tracing. J Neurosci Meth 29:261-265

Duman RS, Tallman JF, Nestler EJ (1988): Acute and chronic opiate regulation of adenylate cyclase in brain: Specific effects in locus coeruleus. J Pharmacol Exp Ther 246:1033-1039

Gomaa AA, Mohamed LH, Ahmed HN (1989): Modification of morphine-induced analgesia, tolerance and dependence by bromocriptine. Eur J Pharmacol 170:129-135

Hakan RL, Callaway C, Henriksen SJ (1989): Electrophysiological analysis of the neural circuitry underlying opiate effects in the nucleus accumbens septi. Neurosci Lett 101:163-168

Hakan RL, Henriksen SJ (1989):Opiate influences on nucleus accumbens neuronal electrophysiology: Dopamine and non-dopamine mechanisms. J Neurosci 9:3538-3546

Harris GC, Aston-Jones G (1993): Beta-adrenergic antagonists attenuate somatic and aversive signs of withdrawal. Neuropsychopharmacology 9:303-311

Harris GC, Aston-Jones G (1994): Involvement of D2 dopamine receptors in the nucleus accumbens in the opiate withdrawal syndrome. Nature 371:155-157

Hays WL (1981): Statistics , 3rd ed. New York, CBS College Publishing

Hayward MD, Duman RS, Nestler EJ (1990): Induction of the c-fos proto-oncogene during opiate withdrawal in 
the locus coeruleus and other regions of rat brain. Brain Res 525:256-266

Kohler C, Fuxe K, Ross SB (1981): Regional in vivo binding of $[3 \mathrm{H}] \mathrm{N}$-propylnorapomorphine in the mouse brain. Evidence for labelling of central dopamine receptors. Eur J Pharmacol 72:397-402

Koob GF, Wall TL, Bloom FE (1989): Nucleus accumbens as a substrate for the aversive stimulus effects of opiate withdrawal. Psychopharmacology 98:530-534

Martin JR, Takemori AE (1987): Modification of the development of acute opiate tolerance by increased dopamine receptor sensitivity. J Pharmacol Exp Ther 241:48-55

McKittrick CR, Delfs JM, Aston-Jones G, Abercrombie ED (1999): Differential spontaneous and withdrawalinduced efflux of catecholamines in nucleus accumbens shell of morphine-treated rats. Soc Neurosci Abstr 25:948

Morgan JI, Curran T (1991): Stimulus-transcription coupling in the nervous system: Involvement of the inducible proto-oncogenes fos and jun. Annu Rev Neurosci 14:421-451

O'Donnell P, Grace AA (1996): Dopaminergic reduction of excitability in nucleus accumbens neurons recorded in vitro. Neuropsychopharmacology 15:87-97

Paxinos G, Watson C (1998): The Rat Brain in Stereotaxic Coordinates, 4th ed. San Diego, Academic Press

Pfaus JG, Marcangione C, Smith WJ, Manitt, C Abillamaa H (1996): Differential induction of Fos in the female rat brain following different amounts of vaginocervical stimulation: Modulation by steroid hormones. Brain Res 741:314-330

Rasmussen K, Brodsky M, Inturrisi CE (1995): NMDA antagonists and clonidine block c-fos expression during morphine withdrawal. Synapse 20:68-74

Rossetti ZL, Hmaidan Y, Gessa GL (1992): Marked inhibition of mesolimbic dopamine release: A common feature of ethanol, morphine, cocaine and amphetamine abstinence in rats. Eur J Pharmacol 221:227-234

Sagar SM, Sharp FR, Curran T (1988): Expression of c-fos protein in brain: Metabolic mapping at the cellular level. Science 240:1328-1331

Schulteis G, Koob GF (1996): Reinforcement processes in opiate addiction: A homeostatic model. Neurochem Res 21:1437-1454
Schulz R, Herz A (1977): Naloxone-precipitated withdrawal reveals sensitization to neurotransmitters in morphine tolerant/dependent rats. Naunyn Schmiedebergs Arch Pharmacol 299:95-99

Shaham Y, Rajabi H, Stewart J (1996): Relapse to heroinseeking in rats under opioid maintenance: The effects of stress, heroin priming, and withdrawal. J Neurosci 16:1957-1963

Stinus L, Le Moal M, Koob GF (1990): Nucleus accumbens and amygdala are possible substrates for the aversive stimulus effects of opiate withdrawal. Neurosci 37:767773

Stone EA, Zhang Y, Carr KD (1995): Massive activation of c-fos in forebrain after mechanical stimulation of the locus coeruleus. Brain Res Bull 36:77-80

Stone EA, Zhang Y, John SM, Bing G (1991): c-Fos response to administration of catecholamines into brain by microdialysis. Neurosci Lett 133:33-35

Stornetta RL, Norton FE, Guyenet, PG (1993): Autonomic areas of rat brain exhibit increased Fos-like immunoreactivity during opiate withdrawal in rats. Brain Res 624:19-28

Terwilliger RZ, Beitner-Johnson D, Sevarino K, Crain S, Nestler EJ (1991): A general role for adaptations in G-proteins and the cyclic AMP system in mediating the chronic actions of morphine and cocaine on neuronal function. Brain Res 548:100-110

Titeler M, Seeman P (1979): Selective labelling of different dopamine receptors by a new agonist $3 \mathrm{H}$-ligand: $3 \mathrm{H}-\mathrm{N}-$ propylnorapomorphine. Eur J Pharmacol 56:291-292

White FJ, Wang RY (1986): Electrophysiological evidence for the existence of both D-1 and D-2 dopamine receptors in the rat nucleus accumbens. J Neurosci 6:274-280

Yuan XR, Madamba S, Siggins GR (1992): Opioid peptides reduce synaptic transmission in the nucleus accumbens. Neurosci Lett 134:223-228

Zahm DS, Brog JS (1992): On the significance of subterritories in the "accumbens" part of the rat ventral striatum. Neurosciences 50:751-767

Zhu Y, Walters C, Wilent B, Druhan J, Aston-Jones G (1997): The bed nucleus of the stria terminalis (BST): A potential target site for noradrenergic actions in opiate withdrawal. Soc Neurosci Abstr 23:1108 